\title{
Vitamin D protects against necrotising enterocolitis in newborn mice by activating the ERK signalling pathway
}

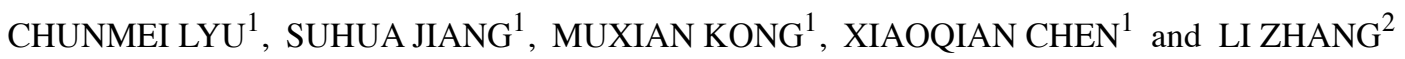 \\ Departments of ${ }^{1}$ Pediatrics and ${ }^{2}$ Nursing, The First People's Hospital of Foshan, \\ Foshan, Guangdong 528000, P.R. China
}

Received January 21, 2020; Accepted May 21, 2020

DOI: $10.3892 / \mathrm{mmr} .2020 .11286$

\begin{abstract}
Necrotising enterocolitis (NEC) is a serious intestinal disease that occurs in the neonatal period. The present study aimed to investigate the protective effect of vitamin D on NEC and the underlying mechanisms. Artificial feeding and hypoxia-cold stimulation were used to establish a mouse NEC model. IEC-6 cells were treated with lipopolysaccharide (LPS) to establish the in vitro NEC model. Changes in the levels of interleukin (IL)-6, IL-1 $\beta$ and tumour necrosis factor (TNF)- $\alpha$, and activities of malondialdehyde (MDA) and glutathione peroxidase (GPx) were investigated via ELISA kits. In addition, mRNA expression of IL- 6 , IL- $1 \beta$ and TNF- $\alpha$ and protein expression of phosphorylated (p)-ERK1/2, Ki67, cleaved caspase- 3 and $\mathrm{Bcl}-2$ in intestinal tissues were determined via reverse transcription-quantitative PCR and western blotting. Cell proliferation and apoptosis were also analysed via MTT assay and flow cytometry. In NEC mice, vitamin D reduced intestinal tissue damage, decreased the mRNA expression of IL-6, IL-1 $\beta$ and TNF- $\alpha$, and decreased the protein expression of cleaved caspase- 3 and MDA. Whereas, vitamin D increased the protein expression of $\mathrm{Bcl}-2$ and $\mathrm{Ki} 67$ and GPx, as well as the p-ERK1/2/ERK1/2 ratio, in NEC mice. Furthermore, vitamin D improved cell viability, increased the ratio of p-ERK1/2/ERK1/2, inhibited apoptosis, and decreased the mRNA expression of IL- 6 , IL- $1 \beta$ and TNF- $\alpha$ in LPS-treated IEC- 6 cells. The dual-specificity mitogen-activated protein kinase kinase inhibitor PD98059 reversed the effects of vitamin $\mathrm{D}$ on the proliferation, apoptosis and inflammation of LPS-treated IEC-6 cells. Overall, vitamin D relieved NEC in mice. Vitamin D promoted proliferation, and inhibited apoptosis and inflammation of LPS-treated IEC-6 cells by activating the ERK signalling pathway.
\end{abstract}

Correspondence to: Dr Li Zhang, Department of Nursing, The First People's Hospital of Foshan, 81 North Lingnan Avenue, Chancheng, Foshan, Guangdong 528000, P.R. China

E-mail: jnzhangli239@163.com

Key words: necrotising enterocolitis, inflammation, proliferation, apoptosis, ERK signalling pathway

\section{Introduction}

Necrotising enterocolitis (NEC) is one of the main causes of neonatal gastrointestinal disease-associated death, which primarily occurs in premature and low birth weight infants (1). The main clinical manifestations of NEC are abdominal distention, diarrhoea and blood in stool, and patients with severe forms of the disease may have intestinal perforation or stenosis, peritonitis, sepsis and intestinal fistula (2). With the development of perinatal medicine and the establishment of neonatal intensive care units, the survival rate of premature infants and infants with a very low birth weight has increased significantly, and the incidence rate of NEC has increased rapidly (3). A large number of in vitro studies and clinical studies have investigated NEC $(4,5)$. However, the pathogenesis of the disease remains unclear. Therefore, it is necessary to explore the mechanisms underlying pathogenesis to inform effective strategies for the treatment of NEC.

Vitamin D participates in cell differentiation, proliferation and inflammation, and it acts as a key component in bone metabolism and calcium homeostasis by interacting with the vitamin D receptor (VDR) (6,7). Clinical research has shown that deficiency of serum vitamin $\mathrm{D}$ is a high-risk factor for inflammatory bowel disease (IBD) and is associated with IBD duration and prognosis (8). Vitamin D deficiency is common in preterm labour, especially in premature infants born before 32 weeks of gestation (9). Du et al (10) confirmed that 1,25-dihydroxyvitamin D protects the intestinal epithelial barrier by regulating the myosin light-chain kinase signalling pathway in a mouse model of 2,4,6-trinitrobenzene sulfonic acid-induced colitis. However, the possible protective mechanism of vitamin D against NEC remains unclear.

ERK1/2 is a member of the mitogen-activated protein kinase family of proteins, the members of which transmit regulatory signals involved in cell proliferation, apoptosis or differentiation (11-14). Bai et al (15) reported that sesamin enhances NADH-dependent flavin reductase subunit 2-mediated defence against oxidative stress and inflammation in ulcerative colitis by activating AKT/ERK. Dai et al (16) revealed that VSL\#3 probiotics protect the intestinal epithelial barrier in acute colitis rats by activating ERK signalling pathways. Bai et al (17) demonstrated that serine/threonine-protein kinase Sgk1 protects intestinal epithelial cells against tumour necrosis factor 
(TNF)- $\alpha$-induced apoptosis in colitis partly by activating the dual-specificity mitogen-activated protein kinase kinase (MEK)/ERK signalling pathway. These studies demonstrate that the ERK signalling pathway plays an important regulatory role in colitis; however, the specific regulatory role of this pathway in NEC remains unclear. In addition, Yuan et al (18) revealed that the VDR protects against neurological deficits and neuronal death in rats with global cerebral ischemia by activating the ERK signalling pathway. Therefore, it was hypothesised that vitamin D may protect against NEC by regulating the ERK signalling pathway.

The present study aimed to establish in vitro and in vivo models of NEC. The effects of vitamin D on NEC were then investigated, including pathological changes in intestinal tissue, oxidative stress, inflammation, proliferation and apoptosis of intestinal cells, and the ERK signalling pathway. The findings of the present research may provide a useful theoretical basis for the treatment of NEC.

\section{Materials and methods}

Establishment of an animal model of NEC. In total, $32 \mathrm{C} 57 \mathrm{BL} / 6 \mathrm{~J}$ mice (16 female and 16 male mice; age, 5-6 weeks; weight, 18-25 g) were used for the establishment of the NEC animal model in vivo based on previous studies (19-21). The mice were fostered in a cage and maintained on a 12:12 light/dark cycle at room temperature under dry atmosphere. C57BL/6J mice were purchased from Changzhou Cavens Laboratory Animal Co., Ltd (license no. $\operatorname{SCXK}(\mathrm{Su}) 2016-0010$; Jiangsu, China). The mice were divided into four groups of 8 animals each: i) Control; ii) NEC; iii) vitamin $\mathrm{D}+$ control and; iv) vitamin $\mathrm{D}+\mathrm{NEC}$. Control mice were fed artificial formula (Abbott Pharmaceutical Co., Ltd.) and given normal saline by gavage. NEC mice were fed artificial formula and subjected to hypoxia-cold stimulation. Vitamin D + control mice were fed artificial formula and administered vitamin D $(0.5 \mathrm{~g} / \mathrm{kg} /$ day; Sigma-Aldrich; Merck KGaA) by gavage. Vitamin D + NEC mice were fed artificial formula, subjected to hypoxia-cold stimulation, and given $0.5 \mathrm{~g} / \mathrm{kg} /$ day vitamin $\mathrm{D}$ by gavage. Artificial feeding and hypoxia-cold stimulation were used to establish the NEC model, as previously described (16). Briefly, mice were exposed to hypoxia with $5 \% \mathrm{O}_{2}$ and $95 \% \mathrm{~N}_{2}$ for $1 \mathrm{~min}$; then, they were immediately placed in a $4^{\circ} \mathrm{C}$ cold chamber for $10 \mathrm{~min}$. The hypoxia-cold stimulation was controlled within $1 \mathrm{~h}$ after the meal and performed twice a day for 4 days. The body weight of the mice was measured every day. Upon appearance of clinical signs (abdominal distension, diarrhea and vomiting) of NEC distress ( $~ 96 \mathrm{~h}$ after modelling), the mice were anesthetised by an intraperitoneal injection of $50 \mathrm{mg} / \mathrm{kg}$ pentobarbital sodium. Anesthesia was confirmed when mice presented with symptoms including excitement, convulsion and fainting. They were then sacrificed by cervical dislocation. Intestinal tissues of the mice were collected for follow-up tests. All animal experiments were approved by the Institutional Animal Care and Use Ethics Committee (approval no. L2019-4; Foshan, China).

Histological injury score. The terminal ileum was fixed in $4 \%$ neutral buffered formalin solution for $24 \mathrm{~h}$ at room temperature, embedded in paraffin and cut into sections with a thickness of $3 \mu \mathrm{m}$. Pathological changes were detected using haematoxylin and eosin (H\&E) staining. Briefly, after dewaxing and hydration, sections were stained with hematoxylin (Sigma-Aldrich; Merck KGaA) for $20 \mathrm{~min}$ at room temperature, and then stained with $0.5 \%$ eosin (Sigma-Aldrich; Merck KGaA) for $90 \mathrm{sec}$ at room temperature. Sections were washed with $70 \%$ ethl alcohol to remove the eosin, and were dehydrated with anhydrous alcohol for $1 \mathrm{~min}$. Finally, these sections were treated with xylene I or II (Sigma-Aldrich; Merck KGaA) for $10 \mathrm{~min}$ at room temperature. After blocking the sections with neutral balsam at room temperature for $24 \mathrm{~h}$, images were captured via an Olympus light microscope (magnification, x 200; Nikon Corporation).

Histopathological changes were scored by two blinded evaluators based on the following criteria (22): 0 , normal, no damage; 1, slight submucosal and/or lamina propria separation; 2, moderate separation of submucosa and/or lamina propria and/or oedema in submucosal and muscular layers; 3 , severe separation of the submucosa and/or lamina propria and/or severe oedema in the submucosa and muscular layers, region villous sloughing; and 4, loss of villi, with necrosis. NEC was defined as a histological score $\geq 2$.

ELISA. Intestinal tissues were placed in cold physiological saline $\left(4^{\circ} \mathrm{C}\right)$ to create a tissue homogenate. Next, the tissue homogenate was centrifuged at $10,000 \mathrm{x}$ g for $15 \mathrm{~min}$ at $4^{\circ} \mathrm{C}$ and the supernatant was collected to determine the levels of inflammatory cytokines, including interleukin (IL)-6, IL-1 $\beta$ and TNF- $\alpha$, using IL-6, IL- $1 \beta$ and TNF- $\alpha$ ELISA kits (cat. nos. ab100713, ab100705 and ab208348, respectively; all Abcam) according to the manufacturer's instructions.

Malondialdehyde (MDA) and glutathione peroxidase (GPX) assays. The supernatant of the intestinal homogenate was collected to detect MDA and GPx activity. The Lipid Peroxidation (MDA) assay kit (Sigma-Aldrich; Merck KGaA) was used to detect MDA activity. GPx activity was detected using the Glutathione Peroxidase assay kit (Cayman Chemical Company). The procedures were conducted according to the manufacturers' instructions.

Cell culture and grouping. Rat epithelial IEC-6 cells were used for the establishment of the NEC cell model in vitro based on previous studies (23-25). IEC-6 cells were purchased from Shanghai Kanglang Biotechnology Co., Ltd. (Shanghai, China) and cultured on 96-well plates in DMEM (Sigma-Aldrich; Merck KGaA) supplemented with 10\% FBS (Sigma-Aldrich; Merck KGaA). IEC-6 cells were divided into four groups: i) Control; ii) lipopolysaccharide (LPS); iii) vitamin D + LPS; and iv) vitamin D + PD98059 + LPS. Control cells underwent no treatment. LPS cells were treated with LPS at a concentration of $50 \mu \mathrm{g} / \mathrm{ml}$ for $6 \mathrm{~h}$ at room temperature. Vitamin D + LPS cells were first treated with LPS at a concentration of $50 \mu \mathrm{g} / \mathrm{ml}$ for $6 \mathrm{~h}$ and then with vitamin $\mathrm{D}$ at a concentration of $50 \mathrm{nM}$ for $48 \mathrm{~h}$ at room temperature. Vitamin D + PD98059 + LPS cells were treated first with LPS at a concentration of $50 \mu \mathrm{g} / \mathrm{m}$ for $6 \mathrm{~h}$, then with vitamin $\mathrm{D}$ at a concentration of $50 \mathrm{nM}$ and the 
Table I. Sequences of primers used for reverse transcription quantitative-PCR.

Sequence $\left(5^{\prime}-3 '\right)$

\begin{tabular}{lll}
\cline { 2 - 3 } Primers & \multicolumn{1}{c}{ Forward } & \multicolumn{1}{c}{ Reverse } \\
\hline IL-6 & GATACCACTCCCAACAGAC & CTTTTCTCATTTCCACGAT \\
IL-1 $\beta$ & GTGGTGTGTGACGTTCCCATTA & CCGACAGCACGAGGCTTT \\
TNF- $\alpha$ & TGCAGCAGGACATCAAGTTC & TACGCCTCAGCAGTCTCCTT \\
GAPDH & GCTTCGGCAGCACATATACTAAAAT & CGCTTCACGAATTTGCGTGTCAT
\end{tabular}

IL, interleukin; TNF, tumour necrosis factor.

MEK inhibitor PD98059 (Shanghai BeiZhuo Biotech Co., Ltd.) at a concentration of $5 \mu \mathrm{M}$ for $48 \mathrm{~h}$ at room temperature.

Reverse transcription-quantitative $(R T-q) P C R$. TRIzol ${ }^{\circledR}$ reagent (Thermo Fisher Scientific, Inc.) was used to extract total RNA from intestinal tissues and cells. cDNA synthesis was conducted at $55^{\circ} \mathrm{C}$ using the PrimeScript RT reagent kit (Takara Bio, Inc.) according to the manufacturer's protocols. qPCR was performed with an ABI 7500 quantitative PCR instrument (Applied Biosystems; Thermo Fisher Scientific, Inc.) using SYBR Green Realtime PCR Master mix (Toyobo Life Science). The qPCR thermocycling conditions were as follows: Pre-denaturation at $95^{\circ} \mathrm{C}$ for $10 \mathrm{~min}$, followed by 40 cycles at $95^{\circ} \mathrm{C}$ for $1 \mathrm{~min}$ and $55^{\circ} \mathrm{C}$ for $30 \mathrm{sec}$. The qPCR primers (Table I) were synthesized by Sangon Biotech Co., Ltd. Relative mRNA expression was calculated using the $2^{-\Delta \Delta C q}$ method and GAPDH served as the internal control (26).

Western blotting. Intestinal tissue was homogenized in RIPA protein lysis buffer (Beyotime Institute of Biotechnology) and centrifuged at $4^{\circ} \mathrm{C}$ for $15 \mathrm{~min}$ at $16,000 \mathrm{x} \mathrm{g}$. A BCA Protein assay kit (Thermo Fisher Scientific, Inc.) was used to detect protein concentrations. In total, $50 \mu \mathrm{g}$ protein was loaded on a $10 \%$ gel, resolved using SDS-PAGE and subsequently transferred to PVDF membranes (Thermo Fisher Scientific, Inc.). The membranes were blocked with 5\% BSA for $1 \mathrm{~h}$ at $37^{\circ} \mathrm{C}$ and were then incubated with the primary antibodies against ERK1/2 (1:1,000; cat. no. ab17942; Abcam), Ki67 (1:1,000; cat. no. MA5-14520; Thermo Fisher Scientific, Inc.), p-ERK1/2 (1:1,000; cat. no. 4376; Cell Signalling Technology, Inc.), cleaved caspase-3 (1:1,000; cat. no. 9661; Cell Signalling Technology, Inc.), Bcl-2 (1:1,000; cat. no. 3498; Cell Signalling Technology, Inc.) and GAPDH (1:1,000; cat. no. 5174, Cell Signalling Technology, Inc.) at $4^{\circ} \mathrm{C}$ overnight. The next day, the membranes were washed three times with $0.2 \%$ TBS-Tween-20 solution and incubated with HRP-conjugated goat anti-rabbit immunoglobulin G (1:2,000; cat. no. 31460; Thermo Fisher Scientific, Inc.) for $2 \mathrm{~h}$ at room temperature. An enhanced chemiluminescence detection kit (Beijing Solarbio Science \& Technology Co., Ltd) was used to visualize the protein bands. The intensity of these bands was quantified via Image $\mathrm{Lab}^{\mathrm{TM}}$ 3.0 software (version 3.0; Bio-Rad Laboratories, Inc.)

MTT assay. An MTT assay was used to determine cell proliferation. Briefly, cells were cultured in an incubator with
$5 \% \mathrm{CO}_{2}$ at $37^{\circ} \mathrm{C}$ for $48 \mathrm{~h}$ and then the cells were incubated with $20 \mu 1$ MTT solution (Shanghai Jianglai Biotechnology Co., Ltd.) for $4 \mathrm{~h}$ at $37^{\circ} \mathrm{C}$. Next, medium was replaced with $150 \mu 1 \mathrm{DMSO}$ for $10 \mathrm{~min}$ to promote crystal dissolution. The absorbance of cell suspensions was measured at $570 \mathrm{~nm}$ using a spectrophotometer (Shanghai Onlab Instrument Co., Ltd.). Cell viability was normalized to that of the control group.

Apoptosis assay. An Annexin V-fluorescein isothiocyanate (FITC)/propidium iodide (PI) apoptosis kit (Invitrogen; Thermo Fisher Scientific, Inc.) was used to determine apoptosis of the aforementioned cell groups. Briefly, cells were resuspended in binding buffer and incubated with Annexin V-FITC $(5 \mu \mathrm{l})$ and PI $(5 \mu \mathrm{l})$ for $10 \mathrm{~min}$ at $25^{\circ} \mathrm{C}$. A flow cytometer (DLK0002095; BD Biosciences) was used to determine the apoptosis rate. CellQuest software (version 3.1; BD Biosciences) was used to analyze the data.

Statistical analysis. SPSS version 22.0 statistical software (IBM, Corp.) was used to analyse the experimental data. The data are expressed as mean \pm standard deviation of three independent repeats. One-way ANOVA followed by Tukey's post hoc test was used for comparisons among multiple groups. $\mathrm{P}<0.05$ was considered to indicate a statistically significant difference.

\section{Results}

Vitamin D reduces damage and oxidative stress in intestinal tissues of NEC mice. To determine whether vitamin D has a protective effect on NEC, the body weight of newborn mice was monitored. No significant difference in body weight was found between the control and vitamin D + control group (Fig. 1A). The body weight of mice in the NEC group was lower compared with that of control mice $48 \mathrm{~h}$ after establishing the NEC model $(\mathrm{P}<0.01)$. Notably, compared with the NEC group, the body weight of mice in the vitamin D + NEC group was higher after 72 and $96 \mathrm{~h}$ of modelling $(\mathrm{P}<0.05)$. H\&E staining (Fig. 1B) demonstrated that the intestinal tissue structure of mice was normal in the control and vitamin $\mathrm{D}+$ control group. Mice in the NEC group exhibited severe necrosis and the infiltration of a number of inflammatory cells in intestinal tissues. Notably, necrosis and inflammation in the vitamin D + NEC group were less compared with the NEC group. In NEC group, separation and necrosis of the villous center, submucosal 
A

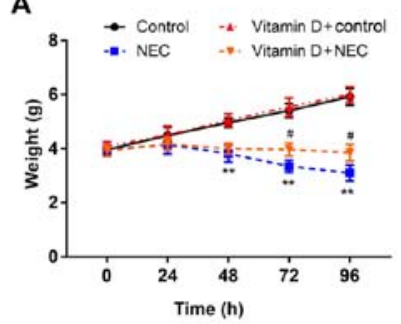

C

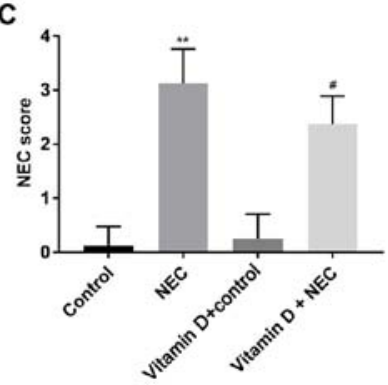

B
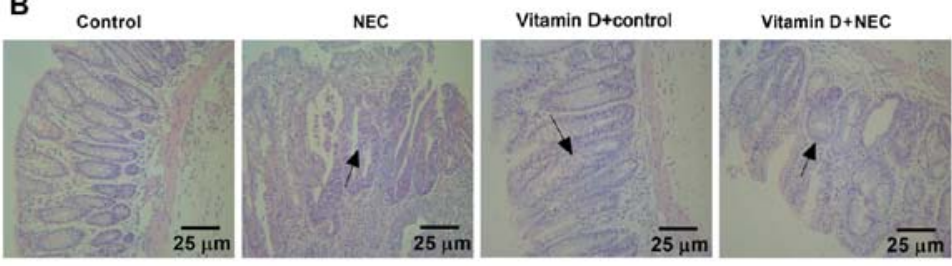

D

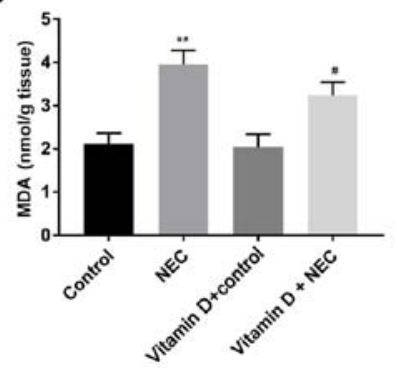

E

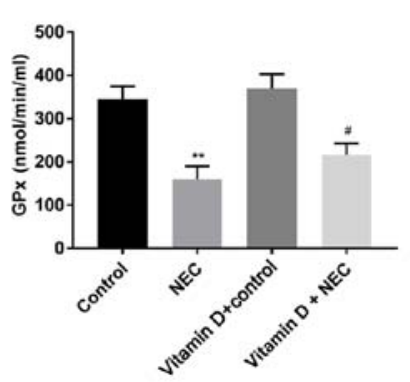

Figure 1. Vitamin D reduces intestinal tissue damage and oxidative stress in NEC mice. (A) Body weight (g) of mice. (B) Histopathological changes were observed by haematoxylin and eosin staining. Arrows indicate necrosis. Scale bar, $25 \mu \mathrm{m}$. (C) Intestinal tissue damage was assessed by NEC score. (D) Levels of MDA in intestinal tissues. (E) Levels of GPx in intestinal tissues. Control mice were given normal saline by gavage under normal environmental conditions $(n=8)$. NEC mice were given normal saline by gavage and treated with hypoxia-cold stimulation $(n=8)$. Vitamin $D+c o n t r o l$ mice were given vitamin $D$ by gavage under normal environmental conditions $(n=8)$. Vitamin $\mathrm{D}+\mathrm{NEC}$ mice were given vitamin $\mathrm{D}$ by gavage and treated with hypoxia-cold stimulation $(\mathrm{n}=8) .{ }^{* *} \mathrm{P}<0.01$ vs. control group. ${ }^{\#} \mathrm{P}<0.05$ vs. the NEC group. NEC, necrotising enterocolitis; MDA, malondialdehyde; GPx, glutathione peroxidase.

edema and epithelial cell beating down were observed; in the vitamin D + NEC group, this phenomenon was significantly improved. Furthermore, the vitamin D + NEC group had a significantly lower NEC score compared with the NEC group $(\mathrm{P}<0.05$; Fig. 1C). As presented in Fig. 1D and E, the levels of MDA were significantly higher, while the GPx levels were significantly lower in the NEC group compared with the control group (both $\mathrm{P}<0.01$ ). Furthermore, vitamin $\mathrm{D}$ intervention in the vitamin D + NEC group significantly decreased the levels of MDA and significantly increased the levels of GPX compared the NEC group (both $\mathrm{P}<0.05$ ).

Vitamin D reduces intestinal inflammatory cytokine levels in NEC mice. Proinflammatory cytokines play important roles in NEC-induced intestinal damage (27). Inflammatory cytokines (IL-6, IL-1 $\beta$ and TNF- $\alpha$ ) in the intestinal tissues of mice were analysed using ELISA and RT-qPCR assays. According to ELISA, no significant differences were observed in the levels of IL- 6 , IL-1 $\beta$ and TNF- $\alpha$ between the control and vitamin D + control groups (Fig. 2A-C). Notably, the levels of IL-6, IL-1 $\beta$ and TNF- $\alpha$ in the NEC group were significantly higher compared with those in the control group (all $\mathrm{P}<0.01$ ). Furthermore, the levels of IL-6, IL-1 $\beta$ and TNF- $\alpha$ were significantly lower in the vitamin D + NEC group compared with the NEC group (all P<0.01). The results of RT-qPCR were consistent with those of ELISA (Fig. 2D-F).

Vitamin D increases the proliferation and decreases the apoptosis of intestinal cells and activates the ERK signalling pathway in NEC mice. The expression levels of ERK signalling pathway- (p-ERK1/2 and ERK1/2), proliferation(Ki67) and apoptosis-associated proteins (cleaved caspase-3 and $\mathrm{Bcl}-2$ ) in the intestinal tissues of mice were analysed using western blotting. As presented in Fig. 3A-E, there were no significant differences in the protein expression levels of p-ERK1/2/ERK1/2, Ki67, cleaved caspase-3 and $\mathrm{Bcl}-2$ between the control and vitamin $\mathrm{D}+$ control groups. Notably, the protein expression levels of Ki67, Bcl-2 and p-ERK1/2/ERK1/2 were significantly lower $(\mathrm{P}<0.01)$, and the protein expression of cleaved caspase-3 was significantly higher $(\mathrm{P}<0.01)$ in the NEC group compared with the control group. Furthermore, the protein expression levels of Ki67, Bcl-2 and p-ERK1/2/ERK1/2 in the vitamin D + NEC group were significantly higher, but the protein expression of cleaved caspase-3 was significantly lower compared with that in the NEC group (all $\mathrm{P}<0.05)$.

Blocking the ERK signalling pathway reverses the protective effect of vitamin D on LPS-treated IEC-6 cells. IEC-6 cells were treated with LPS to establish an in vitro NEC model. As presented in Fig. 4A, the ratio of p-ERK1/2/ERK1/2 was significantly lower in the LPS group compared with the control group $(\mathrm{P}<0.01)$, however the ratio of $\mathrm{p}-\mathrm{ERK} 1 / 2 / \mathrm{ERK} 1 / 2$ was significantly higher in the vitamin D + LPS group compared with the LPS group $(\mathrm{P}<0.01)$. Subsequently, the proliferation and apoptosis of IEC- 6 cells were determined using an MTT assay and flow cytometry, respectively. As presented in Fig. 4B and C, cell viability was significantly decreased and the apoptosis rate was significantly increased in the LPS group compared with the control group (both $\mathrm{P}<0.01$ ). Vitamin $\mathrm{D}$ treatment in the vitamin D + LPS group significantly increased the viability and significantly decreased the rate of apoptosis of IEC-6 cells compared with the LPS group (both $\mathrm{P}<0.01$ ). Furthermore, RT-qPCR revealed that the mRNA expression levels of IL- 6 , IL- $1 \beta$ and TNF- $\alpha$ were significantly increased in the LPS group compared the control group, and vitamin D treatment significantly reversed the effect of LPS 

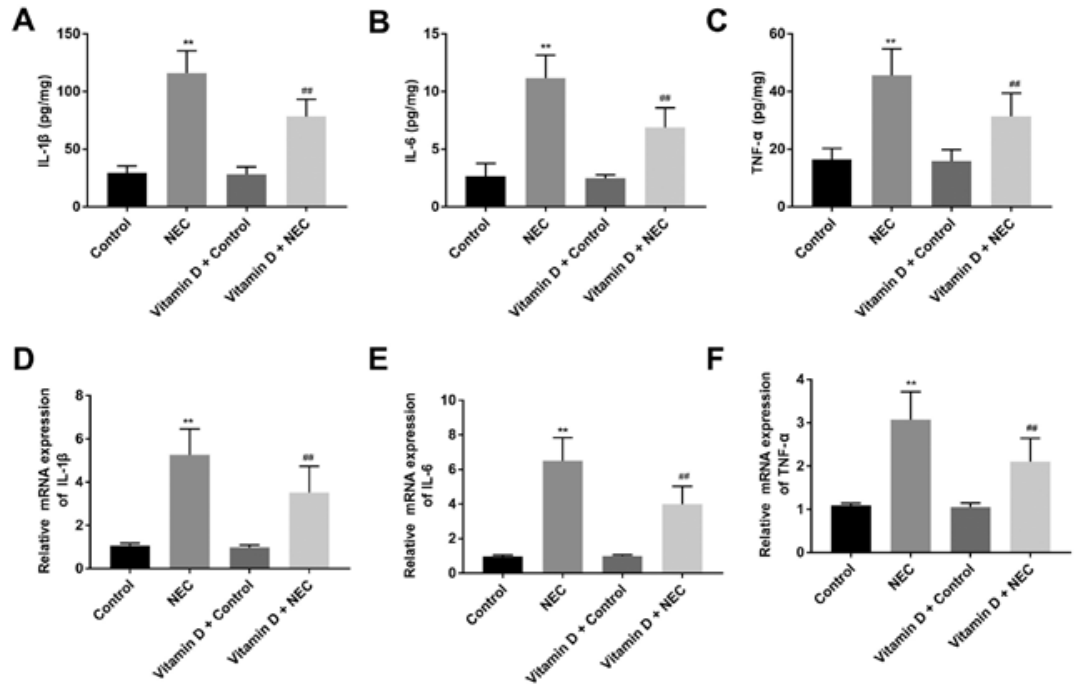

Figure 2. Vitamin D reduces intestinal inflammation in NEC mice. Levels of (A) IL-1 $\beta$, (B) IL-6 and (C) TNF- $\alpha$ in intestinal tissues were detected by ELISA The mRNA expression levels of (D) IL-1 $\beta$, (E) IL-6 and (F) TNF- $\alpha$ in intestinal tissues were detected by reverse transcription quantitative-PCR. Control mice were given normal saline by gavage under normal environmental conditions $(n=8)$. NEC mice were given normal saline by gavage and treated with hypoxia-cold stimulation $(\mathrm{n}=8)$. Vitamin $\mathrm{D}+$ control mice were given vitamin $\mathrm{D}$ by gavage under normal environmental conditions $(\mathrm{n}=8)$. Vitamin $\mathrm{D}+\mathrm{NEC}$ mice were given vitamin $D$ by gavage and treated with hypoxia-cold stimulation $(n=8) .{ }^{* *} \mathrm{P}<0.01$ vs. control group. ${ }^{\# \#} \mathrm{P}<0.01$ vs. NEC group. NEC, necrotising enterocolitis; IL, interleukin; TNF, tumour necrosis factor.
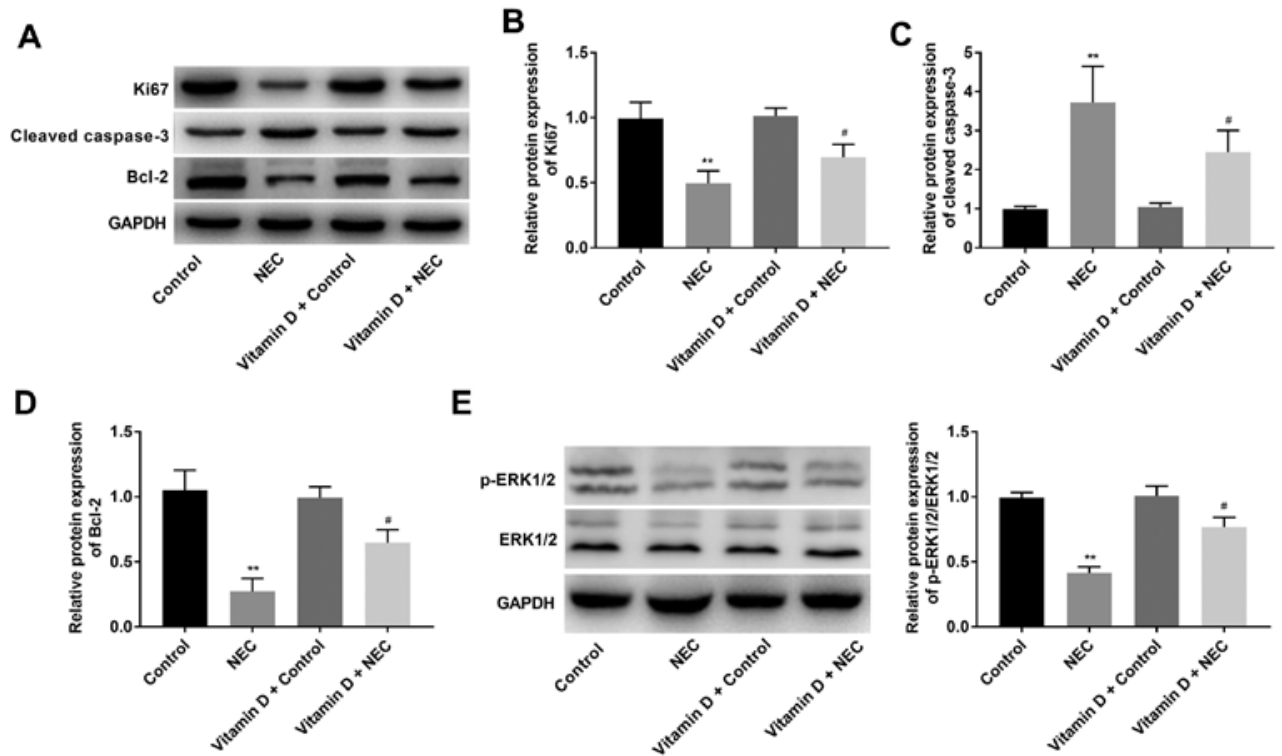

Figure 3. Vitamin D promotes cell growth and activates the ERK signalling pathway in NEC mice. (A) Protein levels of Ki67, cleaved caspase-3 and Bcl-2 in intestinal tissues were detected using western blotting. Protein expression levels of (B) Ki67, (C) cleaved caspase-3, (D) Bcl-2, and (E) p-ERK1/2 and ERK1/2 in intestinal tissues were detected using western blotting. Control mice were given normal saline by gavage under normal environmental conditions ( $\mathrm{n}=8$ ). NEC mice were given normal saline by gavage and treated with hypoxia-cold stimulation $(n=8)$. Vitamin $\mathrm{D}+$ control mice were given vitamin $\mathrm{D}$ by gavage under normal environmental conditions $(\mathrm{n}=8)$. Vitamin $\mathrm{D}+\mathrm{NEC}$ mice were given vitamin $\mathrm{D}$ by gavage and treated with hypoxia-cold stimulation $(\mathrm{n}=8) .{ }^{* *} \mathrm{P}<0.01$ vs. control group. ${ }^{\#} \mathrm{P}<0.05$ vs. NEC group. NEC, necrotising enterocolitis; $\mathrm{p}-$, phosphorylated.

(all P<0.01; Fig. 4D-F). Notably, the MEK inhibitor PD98059 significantly reversed the effects of vitamin D on p-ERK1/2 level, proliferation, apoptosis and inflammatory-associated proteins in IEC-6 cells (Fig. 4A-F).

\section{Discussion}

NEC is a serious intestinal disease that occurs in the neonatal period and it is a common cause of early death in neonates (28). At present, NEC is considered to be caused by premature birth, hypoxia, enteral feeding, bacterial infection and intestinal ischemia (29); however, its pathogenesis is still not completely clear. The results of the present study demonstrated that vitamin $\mathrm{D}$ reduced intestinal tissue damage, oxidative stress and inflammation in NEC mice. Furthermore, vitamin D promoted cell viability, inhibited apoptosis and inflammation, and activated the ERK signalling pathway in LPS-treated IEC-6 cells. 
A

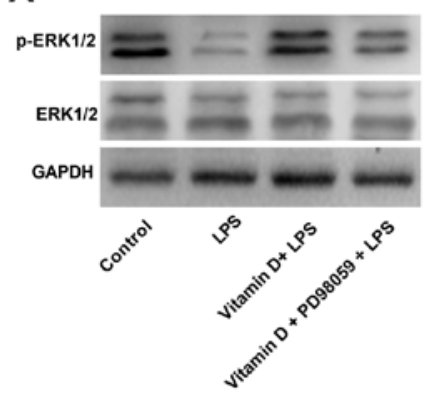

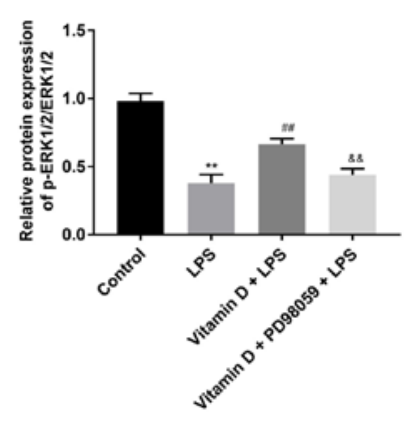

B

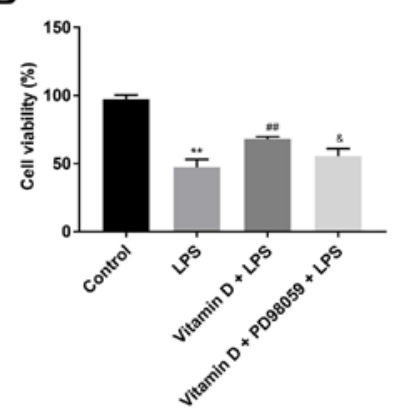

C
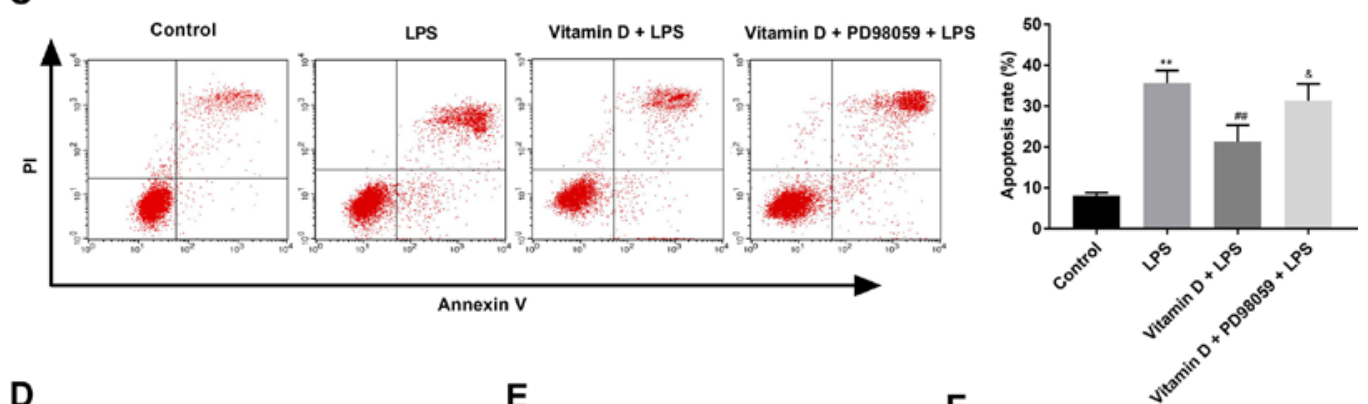

D

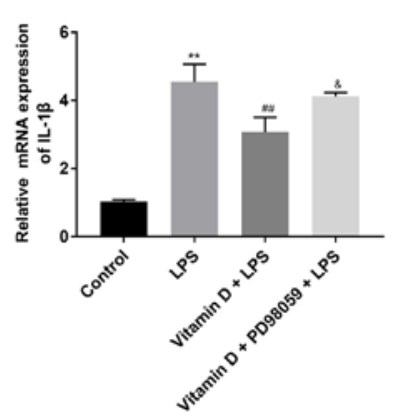

E

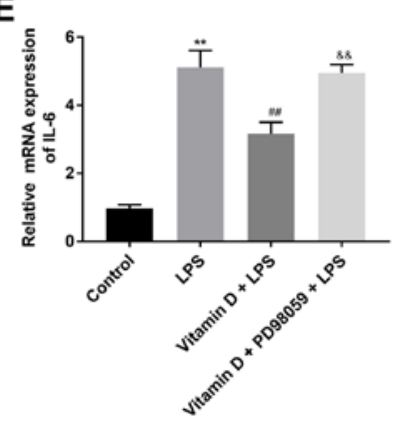

F

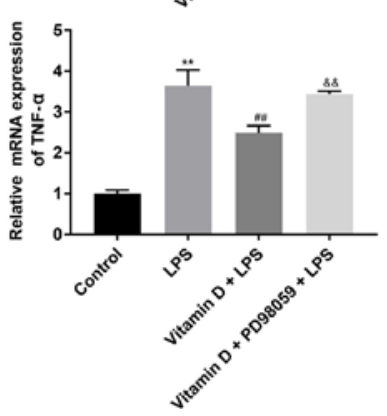

Figure 4. Inhibiting the ERK signalling pathway reverses the protective effect of vitamin D on LPS-induced IEC-6 cells. (A) Protein expression levels of p-ERK1/2 and ERK1/2 in IEC-6 cells were detected using western blotting. (B) Viability of IEC-6 cells was detected using an MTT assay. (C) Apoptosis of IEC- 6 cells was assessed by flow cytometry. mRNA expression of (D) IL-1 $\beta$, (E) IL-6 and (F) TNF- $\alpha$ in IEC- 6 cells was analysed using by reverse transcription quantitative-PCR. Control cells were not treated. LPS cells were treated with LPS only. Vitamin D + LPS cells treated with LPS and vitamin D. Vitamin D + PD98059 + LPS cells treated with LPS, vitamin D and PD98059 (an inhibitor of dual specificity mitogen-activated protein kinase kinase). ${ }^{* *} \mathrm{P}<0.01$ vs. control group. ${ }^{\# \#} \mathrm{P}<0.01$ vs. the LPS group. ${ }^{\circledR} \mathrm{P}<0.05$, \&\& $\mathrm{P}<0.01$ vs. the vitamin $\mathrm{D}+$ LPS group. LPS, lipopolysaccharide; $\mathrm{p}-$, phosphorylated; IL, interleukin; TNF, tumour necrosis factor; FITC, fluorescein isothiocyanate; PI, propidium iodide.

Reactive oxygen species produced by oxidative stress can directly or indirectly damage the physiological functions of proteins, lipids, nucleic acids and other biological macromolecules in cells, which is the pathophysiological basis for the occurrence and development of NEC (30). MDA is a marker of lipid oxidation and an indicator of the degree of membrane damage (31). GPx is a marker of anti-oxidative capacity (32). A prior study revealed that vitamin D3 reduces serum MDA levels in patients with irritable bowel syndrome (33). In an animal model, Farhangi et al (34) reported that vitamin $\mathrm{D}$ treatment leads to a significant reduction in GPx concentrations in the high-fat diet + vitamin D group. The present study demonstrated that vitamin $\mathrm{D}$ treatment decreased MDA and increased GPx levels in the intestinal tissues of NEC mice. These results suggest that vitamin D reduced oxidative stress in the intestinal tissue of NEC mice.

Vitamin D plays a key regulatory role in calcium and phosphorus metabolism and anti-inflammation (35-37). For example, Golan et al (38) conducted experiments using VDR transgenic mice and revealed that overexpression of VDR in the intestinal epithelium inhibits the occurrence of spontaneous enteritis caused by IL-10 deficiency. Liu et al (39) reported that $1,25(\mathrm{OH})_{2} \mathrm{D}_{3}$ (an active form of vitamin $\mathrm{D}$ )-deficient mice exhibit notable colon inflammation phenotypes, and high expression of inflammatory cytokines. Mousavi et al (40) confirmed that 25-OH-cholecalciferol (a circulating form of vitamin D)-treated mice display low compromised colonic epithelial barrier function and low levels of pro-inflammatory mediators including IL-6, MCP1 and IFN- $\gamma$. Consistent with previous results, the present study demonstrated that vitamin $\mathrm{D}$ treatment reduced the levels of inflammatory cytokines (IL-6, IL-1 $\beta$ and TNF- $\alpha$ ) in the intestinal tissue of mice and LPS-treated IEC-6 cells. In brief, the present results suggest that vitamin D reduces inflammation in NEC.

Apoptosis is one of the important pathological changes in intestinal injury during NEC. As reported previously, VDR signalling leads to a reduction in IEC apoptosis by blocking NF- $\kappa B$ activation (41). Zhu et al (42) reported that vitamin D deficiency is common in patients with IBD and that vitamin $\mathrm{D}$ decreases the expression levels of cleaved caspase- 3 in mice with 2,4,6-trinitrobenzene sulfonic acid-induced colitis. He et al (43) found that the absence of gut epithelial VDR 
promotes the apoptosis of epithelial cells and increases the permeability of the mucosal barrier. In the present study, vitamin $\mathrm{D}$ treatment increased the protein expression levels of Bcl-2, decreased the protein expression levels of cleaved caspase- 3 in the intestinal tissue of mice and inhibited the apoptosis of LPS-treated IEC-6 cells. The aforementioned results suggest that vitamin $D$ inhibits the apoptosis of intestinal cells in NEC mice.

Previous studies have reported that the ERK1/2 signalling pathway is involved in the genesis and development of intestinal diseases. For example, Ban et al (44) demonstrated that treatment with U0126 (an ERK1/2 inhibitor) leads to an increase in intestinal permeability, intestinal injury and inflammatory cytokines in mice with intestinal ischemia-reperfusion. Deng et al (45) suggested that leptin reduces intestinal histological alterations and MDA and IL-6 levels by enhancing ERK1/2 phosphorylation and promoting the NO synthesis signalling pathway. Jeong et al (46) revealed that spirulina crude protein treatment promotes cell migration and proliferation, and dysregulates the protein expression of H-Ras, p-Raf-1, p-MEK-1 and p-ERK-1/2 in IEC-6 cells. The present study demonstrated that vitamin $\mathrm{D}$ increased the protein expression levels of p-ERK1/2 in NEC intestinal tissue and IEC-6 cells. Notably, the MEK inhibitor PD98059 reversed the effects of vitamin D on the proliferation, apoptosis and inflammation of LPS-treated IEC-6 cells. The aforementioned findings demonstrate that vitamin D improved cell viability and inhibited cell apoptosis and inflammation in intestinal cells of NEC mice by activating the ERK signalling pathway.

The present study has some limitations. First, the histopathological change of NEC was only observed in the mucosa layer. The observations of different layers of the intestine may better reflect the therapeutic effect of vitamin D on NEC, as each layer exhibits different characteristics. Second, the potential mechanisms underlying the of action of vitamin D still need to be further investigated. For example, the genes and signaling pathways through which vitamin D improves NEC should be elucidated.

In conclusion, vitamin $\mathrm{D}$ reduced intestinal tissue damage, oxidative stress and inflammation, and activated the ERK signalling pathway in NEC mice in the present study. Furthermore, vitamin D promoted the viability, and inhibited the apoptosis and inflammation of LPS-treated IEC- 6 cells by activating the ERK signalling pathway. The present findings may provide a new theoretical basis for the treatment of NEC.

\section{Acknowledgements}

Not applicable.

\section{Funding}

No funding was received.

\section{Availability of data and materials}

The datasets used and/or analysed during the current study are available from the corresponding author on reasonable request.

\section{Authors' contributions}

CL and SJ were mainly responsible for conceptualization, data analysis and interpretation. SJ was responsible for drafting and revising the manuscript. MK performed the experiments. XC and LZ were responsible for software management and visualization. All authors read and approved the final manuscript.

\section{Ethics approval and consent to participate}

All animal experiments were approved by The Institutional Animal Care and Use Ethics Committee (approval no. L2019-4; Foshan, China).

\section{Patient consent for publication}

Not applicable.

\section{Competing interests}

The authors declare that they have no competing interests.

\section{References}

1. Neu $\mathrm{J}$ and Walker WA: Necrotizing enterocolitis. N Engl J Med 364: 255-264, 2011.

2. Guyot D, Kuo P, Pawlotsky F, Papouin-Rauzy M and Delbreil JP: Intestinal fistula: An unusual complication of necrotizing enterocolitis in the preterm infant. Arch Pediatr 16: 435-438, 2009 (In French).

3. Zangari A, Noviello C, Nobile S, Cobellis G, Gulia C, Piergentili R, Gigli S and Carnielli V: Surgical management of Necrotizing Enterocolitis in an Incredibly Low Birth Weight infant and review of the Literature. Clin Ter 168: e297-e299, 2017.

4. Vieten D, Corfield A, Ramani P and Spicer R: Proliferative response in necrotising enterocolitis is insufficient to prevent disease progression. Pediatr Surg Int 22: 50-56, 2006.

5. Llanos AR, Moss ME, Pinzòn MC, Dye T, Sinkin RA and Kendig JW: Epidemiology of neonatal necrotising enterocolitis: A population-based study. Paediatr Perinat Epidemiol 16: 342-349, 2002.

6. Pittas AG, Harris SS, Stark PC and Dawson-Hughes B: The effects of calcium and vitamin D supplementation on blood glucose and markers of inflammation in nondiabetic adults. Diabetes Care 30: 980-986, 2007.

7. Veldurthy V, Wei R, Oz L, Dhawan P, Jeon YH and Christakos S: Vitamin D, calcium homeostasis and aging. Bone Res 4: 16041, 2016.

8. Ardesia M, Ferlazzo G and Fries W: Vitamin D and inflammatory bowel disease. BioMed Res Int 2015: 470805, 2015.

9. Zhu T, Liu TJ, Ge X, Kong J, Zhang LJ and Zhao Q: High prevalence of maternal vitamin D deficiency in preterm births in northeast China, Shenyang. Int J Clin Exp Pathol 8: 1459-1465, 2015.

10. Du J, Chen Y, Shi Y, Liu T, Cao Y, Tang Y, Ge X, Nie H, Zheng C and $\mathrm{Li}$ YC: 1,25-Dihydroxyvitamin $\mathrm{D}$ protects intestinal epithelial barrier by regulating the myosin light chain kinase signaling pathway. Inflamm Bowel Dis 21: 2495-2506, 2015.

11. Li Q, Chen M, Liu H, Yang L, Yang T and He G: The dual role of ERK signaling in the apoptosis of neurons. Front Biosci 19: 1411-1417, 2014.

12. Wang X, Wang Y, Zhu Y, Yan L and Zhao L: Neuroprotective effect of S-trans, trans-farnesylthiosalicylic acid via inhibition of RAS/ERK pathway for the treatment of alzheimer's Disease. Drug Des Devel Ther 13: 4053-4063, 2019.

13. Dziarski R, Jin YP and Gupta D: Differential activation of extracellular signal-regulated kinase (ERK) 1, ERK2, p38, and c-Jun NH2-terminal kinase mitogen-activated protein kinases by bacterial peptidoglycan. J Infect Dis 174: 777-785, 1996.

14. Hu SM, Yao XH, Hao YH, Pan AH and Zhou XW: 8 Gingerol regulates colorectal cancer cell proliferation and migration through the EGFR/STAT/ERK pathway. Int J Oncol 56: 390-397, 2020. 
15. Bai X, Gou X, Cai P, Xu C, Cao L, Zhao Z, Huang M and Jin J: Sesamin enhances Nrf2-mediated protective defense against oxidative stress and inflammation in colitis via AKT and ERK activation. Oxid Med Cell Longev 2019: 2432416, 2019.

16. Dai C, Zhao DH and Jiang M: VSL\#3 probiotics regulate the intestinal epithelial barrier in vivo and in vitro via the p38 and ERK signaling pathways. Int J Mol Med 29: 202-208, 2012.

17. Bai JA, Xu GF, Yan LJ, Zeng WW, Ji QQ, Wu JD and Tang QY: SGK1 inhibits cellular apoptosis and promotes proliferation via the MEK/ERK/p53 pathway in colitis. World J Gastroenterol 21: 6180-6193, 2015

18. Yuan J, Guo X, Liu Z, Zhao X, Feng Y, Song S, Cui C and Jiang P: Vitamin D receptor activation influences the ERK pathway and protects against neurological deficits and neuronal death. Int J Mol Med 41: 364-372, 2018.

19. Ginzel M, Feng X, Kuebler JF, Klemann C, Yu Y, von Wasielewski R, Park JK, Hornef MW, Vieten G, Ure BM, et al: Dextran sodium sulfate (DSS) induces necrotizing enterocolitis-like lesions in neonatal mice. PLoS One 12: e0182732, 2017.

20. Liu Y, Tran DQ, Fatheree NY and Marc Rhoads J: Lactobacillus reuteri DSM 17938 differentially modulates effector memory $\mathrm{T}$ cells and Foxp3+ regulatory T cells in a mouse model of necrotizing enterocolitis. Am J Physiol Gastrointest Liver Physiol 307: G177-G186, 2014.

21. Ginzel M, Yu Y, Klemann C, Feng X, von Wasielewski R, Park JK, Hornef MW, Torow N, Vieten G, Ure BM, et al: The viral dsRNA analogue poly (I:C) induces necrotizing enterocolitis in neonatal mice. Pediatr Res 79: 596-602, 2016.

22. Wu SF, Chiu HY, Chen AC, Lin HY, Lin HC and Caplan M: Efficacy of different probiotic combinations on death and necrotizing enterocolitis in a premature rat model. J Pediatr Gastroenterol Nutr 57: 23-28, 2013.

23. Zhang D, Wen J, Zhou J, Cai W and Qian L: Milk fat globule membrane ameliorates necrotizing enterocolitis in neonatal rats and suppresses lipopolysaccharide-induced inflammatory response in IEC-6 enterocytes. JPEN J Parenter Enteral Nutr 43: 863-873, 2019.

24. Maynard AA, Dvorak K, Khailova L, Dobrenen H, Arganbright KM, Halpern MD, Kurundkar AR, Maheshwari A and Dvorak B: Epidermal growth factor reduces autophagy in intestinal epithelium and in the rat model of necrotizing enterocolitis. Am J Physiol Gastrointest Liver Physiol 299: G614-G622, 2010.

25. Zhou Y, Li Y, Zhou B, Chen K, Lyv Z, Huang D, Liu B, Xu Z, Xiang B, Jin S, et al: Inflammation and apoptosis: dual mediator role for toll-like receptor 4 in the development of necrotizing enterocolitis. Inflamm Bowel Dis 23: 44-56, 2017.

26. Livak KJ and Schmittgen TD: Analysis of relative gene expression data using real-time quantitative PCR and the $2(-\Delta \Delta$ C(T)) Method. Methods 25: 402-408, 2001.

27. Korkut S, Özdemir A, Yay AH, Yalçın B, Ceylan M, Korkmaz L, Yazıcı C, Güntürk İ and Kurtoğlu S: Obestatin reduces intestinal damage in experimental necrotizing enterocolitis in newborn rats. Am J Perinatol 36: 1179-1187, 2019.

28. Rolnitsky A, Ng E, Asztalos E, Shama Y, Karol D, Findlater C, Garsch M and Dunn M: A quality improvement intervention to reduce necrotizing enterocolitis in premature infants with probiotic supplementation. Pediatr Qual Saf 4: e201, 2019.

29. Rose AT and Patel RM: A critical analysis of risk factors for necrotizing enterocolitis. Semin Fetal Neonatal Med 23: 374-379, 2018.

30. Aceti A, Beghetti I, Martini S, Faldella G and Corvaglia L: Oxidative stress and necrotizing enterocolitis: Pathogenetic mechanisms, opportunities for intervention, and role of human milk. Oxid Med Cell Longev 2018: 7397659, 2018.
31. Zhang D, Wen J, Zhou J, Cai W and Qian L: Milk fat globule membrane ameliorates necrotizing enterocolitis in neonatal rats and suppresses lipopolysaccharide-induced inflammatory response in IEC-6 enterocytes. JPEN J Parenter Enteral Nutr 43 : 863-873, 2019.

32. Klinke M, Vincent D, Trochimiuk M, Appl B, Tiemann B, Bergholz R, Reinshagen K and Boettcher M: Degradation of extracellular DNA significantly ameliorates necrotizing enterocolitis severity in mice. J Surg Res 235: 513-520, 2019.

33. Amani R, Abbasnezhad A, Hajiani E, Cheraghian B, Abdoli Z and Choghakhori R: Vitamin D3 induced decrease in IL-17 and malondialdehyde, and increase in IL-10 and total antioxidant capacity levels in patients with irritable bowel syndrome. Iran J Immunol 15: 186-196, 2018.

34. Farhangi MA, Mesgari-Abbasi M, Hajiluian G, Nameni G and Shahabi P: Adipose tissue inflammation and oxidative stress: The ameliorative effects of vitamin D. Inflammation 40: 1688-1697, 2017.

35. Kühne H, Hause G, Grundmann SM, Schutkowski A, Brandsch C and Stangl GI: Vitamin D receptor knockout mice exhibit elongated intestinal microvilli and increased ezrin expression. Nutr Res 36: 184-192, 2016

36. Dauletbaev N, Herscovitch K, Das M, Chen H, Bernier J, Matouk E, Bérubé J, Rousseau S and Lands LC: Down-regulation of IL-8 by high-dose vitamin D is specific to hyperinflammatory macrophages and involves mechanisms beyond up-regulation of DUSP1. Br J Pharmacol 172: 4757-4771, 2015.

37. Holick MF: Vitamin D deficiency. N Engl J Med 357: 266-281, 2007.

38. Golan MA, Liu W, Shi Y, Chen L, Wang J, Liu T and Li YC: Transgenic expression of vitamin D receptor in gut epithelial cells ameliorates spontaneous colitis caused by Interleukin-10 deficiency. Dig Dis Sci 60: 1941-1947, 2015.

39. Liu Y, Chen L, Zhi C, Shen M, Sun W, Miao D and Yuan X: $1,25(\mathrm{OH}) 2 \mathrm{D} 3$ deficiency induces colon inflammation via secretion of senescence-associated inflammatory cytokines. PLoS One 11: e0146426, 2016.

40. Mousavi S,Lobo de SáFD, Schulzke JD,Bücker R, Bereswill S and Heimesaat MM: Vitamin D in Acute Campylobacteriosis-Results From an Intervention Study Applying a Clinical Campylobacter jejuni Induced Enterocolitis Model. Front Immunol 10: 2094 2019.

41. Liu W, Chen Y, Golan MA, Annunziata ML, Du J, Dougherty U, Kong J, Musch M, Huang Y, Pekow J, et al: Intestinal epithelial vitamin D receptor signaling inhibits experimental colitis. J Clin Invest 123: 3983-3996, 2013.

42. Zhu T, Liu TJ, Shi YY and Zhao Q: Vitamin D/VDR signaling pathway ameliorates 2,4,6-trinitrobenzene sulfonic acid-induced colitis by inhibiting intestinal epithelial apoptosis. Int J Mol Med 35: 1213-1218, 2015.

43. He L, Liu T, Shi Y, Tian F, Hu H, Deb DK, Chen Y, Bissonnette M and $\mathrm{Li}$ YC: Gut epithelial vitamin $\mathrm{D}$ receptor regulates microbiota-dependent mucosal inflammation by suppressing intestinal epithelial cell apoptosis. Endocrinology 159: 967-979, 2018.

44. Ban K, Peng Z and Kozar RA: Inhibition of ERK1/2 worsens intestinal ischemia/reperfusion injury. PLoS One 8: e76790, 2013.

45. Deng ZH Jr, Yan GT, Wang LH, Zhang JY, Xue H and Zhang K: Leptin relieves intestinal ischemia/reperfusion injury by promoting ERK1/2 phosphorylation and the NO signaling pathway. J Trauma Acute Care Surg 72: 143-149, 2012.

46. Jeong SJ, Choi JW, Lee MK, Choi YH and Nam TJ: Spirulina crude protein promotes the migration and proliferation in IEC- 6 cells by activating EGFR/MAPK signaling pathway. Mar Drugs 17: 205, 2019. 